\title{
THE INFLUENCE OF MUSCLES ACTIVATION ON DYNAMICAL BEHAVIOR OF THE TYMPANO-OSSICULAR SYSTEM OF THE MIDDLE EAR
}

\author{
FERNANDA GENTIL \\ IDMEC - Faculdade de Engenharia da Universidade do Porto \\ Clínica ORL - Dr. Eurico Almeida, ESTSP, WIDEX, Lda \\ Rua Dr. Roberto Frias s/n, 4200-465 Porto, Portugal \\ e-mail: fernanda.fgnanda@gmail.com \\ MARCO PARENTE, PEDRO MARTINS, CAROLINA GARBE, \\ IDMEC - Faculdade de Engenharia da Universidade do Porto \\ Rua Dr. Roberto Frias s/n, 4200-465 Porto, Portugal \\ e-mail: mparente@fe.up.pt, palsm@fe.up.pt, garbe@fe.up.pt
}

\author{
JOÃO PAÇO \\ Hospital CUF - Faculdade de Medicina da Universidade de Lisboa, Portugal \\ Av. Prof. Egas Moniz - Cidade Universitária - 1649-028 Lisboa \\ e-mail: Joao.Paco@jmellosaude.pt
}

\begin{abstract}
A.J.M. FERREIRA, JOÃO MANUEL R. S. TAVARES
INEGI - Faculdade de Engenharia da Universidade do Porto

Rua Dr. Roberto Frias, s/n, 4200-465 Porto, Portugal

e-mail: ferreira@fe.up.pt, tavares@fe.up.pt
\end{abstract}

RENATO NATAL JORGE

IDMEC - Faculdade de Engenharia da Universidade do Porto

Rua Dr. Roberto Frias s/n, 4200-465 Porto, Portugal

e-mail: rnatal@fe.up.pt

Key words: Biomechanics, Finite Elements, Middle ear, Muscles.

Summary. The human ear is a complex biomechanical system and is divided into three parts: outer, middle and inner ear. The middle ear is formed by ossicles (malleus, incus and stapes), ligaments, muscles and tendons, that transfer sound vibrations from the eardrum to the inner ear, linking with mastoid and Eustachian tube. In this work, a finite element modelling of the tympano-ossicular system of the middle ear was developed. A dynamic study based on a structural response to harmonic vibrations, for a sound pressure level of 110, 120 and $130 \mathrm{~dB}$ SPL applied in the eardrum, is presented. The connection between ossicles is done using a contact formulation. The model includes the different ligaments considering its hyperelastic behaviour. The activation of the muscles is based on the constitutive model proposed by previous work. Harmonic responses of displacement and pressure obtained on the stapes footplate, for a frequency range between $100 \mathrm{~Hz}$ and $10 \mathrm{kHz}$, are obtained simulating the muscle activation. The results are compared considering the passive and active states. The results are discussed and they are in accordance with audiological data published referent to the effects of the middle ear muscles contraction. 


\section{INTRODUCTION}

The human ear can detect and appreciate an enormous quantity of sounds. The perception of loudness and pitch are related with intensity and frequency, respectively. Humans can generally hear sounds with intensities between $0 \mathrm{~dB}$ and $130 \mathrm{~dB}$ and frequencies between $16 \mathrm{~Hz}$ and $20 \mathrm{kHz}$. Sound pressure level (SPL) is a logarithmic measure of the effective sound pressure of a sound relative to a reference value. It is measured in decibels $(\mathrm{dB})$ above a standard reference level. The "zero" reference sound pressure in air is $20 \mu \mathrm{Pa}$, which is considered the threshold of human hearing (at $1 \mathrm{kHz}$ ). (Zemlin 1988).

The ear is able to convert the vibrations of sound into electrical signals that are sent to the brain, where they are perceived.

A hearing loss is a full or partial decrease in the ability to detect or understand sounds. It can occur at any age and makes verbal communication difficult. Hearing impairment is measured by the amount of level of loss in what are called decibels (dB) hearing level (HL). The normal range of hearing is 0 to $25 \mathrm{~dB}$ HL. If the hearing is above $25 \mathrm{~dB}$ HL, the loss may be mild, moderate, severe or profound (Tilman 2005). Medication, surgery or hearing aids are used when problems with some parts of the ear occur. The severity of a hearing impairment is categorized as conductive, sensorineural and mixed (Isaacson et al. 2003).

Conductive hearing loss may be caused by a mechanical dysfunction in the external or middle ear, as wax in the external ear canal, infections, allergies, Eustachian tube blockage, eardrum perforations, myringosclerosis, tympanosclerosis, otosclerosis and tumours (Paço 2003).

Sensorineural hearing loss occurs when there is a problem in the inner ear, or in the central processing centres of the brain that can include inherited disorders, noise exposure, Ménière's disease, presbycusis, central hearing losses and tumours. Mixed hearing loss is concomitant conductive and sensorineural loss.

Hearing sensitivity is indicated by the quietest sound that an individual can detect, called the hearing threshold, which can be measured by a behavioural audiogram. The test is carried out for sounds of different frequencies (normally $125 \mathrm{~Hz}$ to $8 \mathrm{kHz}$ ) and intensities between $-10 \mathrm{~dB}$ and 120 $\mathrm{dB}$. There is another aspect to hearing that involves the quality of a sound that is usually measured by tests of speech discrimination. Basically, these tests require that the sound is not only detected but understood. The percentage of words correctly repeated is the discrimination score (Katz et al. 1991).

To determine the middle ear impedance two tests can be made: tympanometry and acoustic reflex determination. Tympanometry measures the sound reflection from the eardrum and aids assessment of the external and middle ear system. Abnormal results suggest a conductive hearing loss.

The acoustic reflex threshold is a stapedius muscle measurement to higher intensity and adequate duration sounds for individual frequencies. Usually, the acoustic reflex thresholds are determined in response to stimuli of 500,1k, $2 \mathrm{k}$, and $4 \mathrm{k} \mathrm{Hz}$. There are two kinds of acoustic reflex: ipsilateral and contralateral. For the determination of ipsilateral, one stimulates the same ear that is monitored for response. For the contralateral, the stimulus is presented to the ear opposite the ear that is monitored for response. Thresholds vary according to individual hearing sensitivity. For a person with normal hearing, the range for acoustic reflex averages is 70 to $100 \mathrm{~dB}$ SPL. If there is a conductive hearing loss, it can be absent. For sensorineural hearing loss, the thresholds may be within the normal range, particularly for moderate hearing losses with recruitment (Stach 1987).

In order to better understand the middle ear function, the correct modeling of the vibro-acoustic behavior is fundamental, as discussed by many authors (Prendergast et al. 1999; Sun et al. 2002; Koike et al. 2002; Gan et al. 2004).

However, in these published works, studies that provided the performance of middle ear muscles and its effects were not found.

In this work, a finite element model of the middle ear is presented, in order to study the effects of muscle activation in the biomechanical response of the tympano-ossicular system. For this purpose, the study starts with an approximate 3D solid model of the ossicles and eardrum, for a normal ear, 
built from computerized tomography images (Gentil 2008). The discretization of the model components is made using tetrahedral solid elements for the ossicles and hexahedral for the eardrum. The model includes different ligaments of the support structure: three ligaments of malleus (superior, lateral and anterior), two ligaments of incus (superior and posterior) and the annular ligament of the stapes (Testut 1920). Two muscles, tensor tympani (TTM) and stapedius (SM) are also considered, as well as their activation. The numerical simulation is conducted with the ABAQUS software (ABAQUS 2007). The Hyperelastic behaviour of these ligaments is taken into account, (Martins et al. 2006). The constitutive law for the muscles is based on the Hill model (Martins et al. 1998). For the ossicles and eardrum, the mechanical properties available in the literature are considered (Prendergast et al.1999; Sun et al. 2002; Gan et al. 2004).

The present finite element model simulates the effect of muscles, namely its activation, on the mechanical behaviour of tympano-ossicular chain of the middle ear. Based on the experimental findings, their influence on the movements of the stapes footplate can be confirmed. The influence of muscles, in situations such as muscle damage or even muscle loss, can also be analysed by finite element simulations.

\section{ANATOMOPHYSIOLOGY OF THE EAR}

The ear is made up of three different parts (Testut 1920): the external, middle and the inner ear. These parts work together so one can hear and process sounds (Figure 1). The external ear is divided by pinna and external auditory canal. The pinna picks up sound waves that travel through the external auditory canal and hit the eardrum. It starts to vibrate and induces movement on three tiny bones (malleus, incus and stapes) in the middle ear. In the eardrum, the acoustical energy is transformed into mechanical energy that is transmitted along on its travel into the inner ear.

\section{Figure 1}

The eardrum is an ovoid, three-layered structure consisting laterally of squamous epithelium, medially, respiratory mucosa and an interwoven fibrous layer (Paço 2009). Normally, it has a conical shape, with the apex maintained medially by the support of the malleus. The fibrous layer thickens laterally to form the annulus, an incomplete ring which is attached to surrounding bone. Superior to the lateral process of the malleus, this ring is deficient, and this area is known as the pars flaccida. The majority of the eardrum is composed of the pars tensa.

\section{Figure 2}

The malleus is connected to the centre of the inner side of the eardrum. The central bulge, where the malleus attaches to the eardrum, is called umbo. The malleus is connected to the incus, which is attached to the stapes (Figure 2). The other end of the stapes, known as footplate, rests against the cochlea, through the oval window. The stapes acts as a piston, creating waves in the inner-ear fluid. Here, mechanical energy is converted into hydraulic one. The vibrations travel to the cochlea, which is filled with liquid and lined with cells that change the sound vibrations, into nerve signals (electrical energy) and, then, pass to the brain, where the sound can be interpreted.

The ossicles are connected with the walls of the tympanic cavity by ligaments (Gray 1918): three for the malleus (anterior, superior and lateral), two for the incus (superior and posterior) and one for the stapes (annular).

The middle ear contains two tiny muscles that can influence the transmission of sound by the ossicular chain (Figure 2). The movement of the ossicles may be stiffened by the TTM (the longer muscle) and SM (the smallest striated muscle in the human body) that are under the control of the trigeminal and facial nerves, respectively. The TTM emerges from a bony canal just above the opening of the Eustachian tube, and runs backward and then outward, as it changes direction in 
passing over a projection of bone. The tendon of this muscle is attached to the upper part of the handle of the malleus. The SM is inserted in the neck of the stapes near of the posterior crus; it contracts in response to a loud noise, making the chain of ossicles more rigid so that less sound is transmitted. Contraction of the TTM pulls the handle of the malleus inward and tenses the tympanic membrane. Contraction of the SM pulls the stapes footplate outward from the oval window. This response, called the acoustic reflex, helps to protect the delicate inner ear from sound damage.

There are two types of acoustic reflex: ipsilateral and contralateral. The assessed pathway for the ipsilateral acoustic reflex, involves the cochlea, ventral cochlear nucleus, superior olivary complex motor nucleus of facial nerve and the stapedius muscle.

For the contralateral or crossed acoustic reflex, the assessed pathway involves the ipsilateral cochlea, ventral cochlear nucleus, and superior olivary complex. The pathway crosses the trapezoid body and then involves the contralateral medial superior olive, the contralateral motor nucleus of facial nerve and the contralateral stapedius muscle (Katz et al. 1991).

Middle ear muscles contribute to increase the resistance to noise. The pathologies that can cause more damage to the middle ear muscles are tympanosclerosis, otosclerosis or facial paralysis. The tympanosclerosis is prone to affect more the tensor tympanic muscle and the otosclerosis the stapedius muscle. In cases of facial paralysis, an injury to the chorda tympanic fibers causes paralysis of the stapedius muscle. Damaged control of stapedius muscle results in hyperacusis, a condition in which normal sounds seem very loud and they can be uncomfortable. It is known that the stapedius reflex has a protective function against low frequency sound exposure.

A muscle is a soft tissue consisting of contractile cells (Herman 2007). Within the cells are myofibrils that contain sarcomeres, which are composed of actin and myosin. Individual muscle fibres are surrounded by endomysium. Muscle fibers are bound by perimysium into bundles called fascicles; the bundles are then grouped to form a muscle, which is enclosed in a sheath of epimysium (Figure 3). Muscle spindles are distributed throughout the muscles and provide sensory feedback information to the central nervous system (Fung 1981).

Figure 3

\section{FINITE ELEMENT ANALYSIS}

\subsection{Finite element model}

The geometry of the eardrum and ossicles (malleus, incus and stapes) was built from computerized tomography images. These images were obtained from a 65 years old woman, without any ear pathology, and the slices have $0.5 \mathrm{~mm}$ of thickness (Gentil et al. 2009). The geometry for the mesh was made from slices with $1 \mathrm{~mm}$ separation. Based on this geometry, a finite element mesh was then carried out, including the ligaments, superior, lateral and anterior of the malleus, superior and posterior of the incus, annular ligament of the stapes and two muscles, the TTM and the SM (Figure 4).

\section{Figure 4}

The numerical simulations were run on a personal laptop (Intel Core i7-620M-2.66 GHz cpu, 8 GB DDR3 RAM, 256 GB SSD hard disk). The default ABAQUS direct solver for sparse matrices was used to solve the system of equations resulting from the finite element method. Each numerical simulation took approximately 20 minutes to complete.

For the finite element model, a total of 81660 elements were used (11165 for the eardrum, 18841 for the malleus, 39228 for the incus, 9218 for the stapes and the remaining for the ligaments and muscles) with a total of 33597 nodes (15295 for the eardrum, 3932 for the malleus, 8373 for the incus and 2849 for the stapes and the remaining for the ligaments and muscles). The number of degrees of freedom reported by the software was 196400 . 
The elements of the ossicles are four tetrahedral nodes (C3D4 in the ABAQUS software) and the eardrum is modelled by hexahedral (C3D8) elements. The three layers of the eardrum were taken into account. The internal and external layers were considered isotropic and the middle one, fibrous, was considered orthotropic (Garbe et al. 2009). The ligaments and muscles are modelled using linear elements of type T3D2.

In order to simulate the hyperelastic behavior for the ligaments, a constitutive model provided by ABAQUS was used, namely the Yeoh constitutive model. The constitutive equations for the hyperelastic behavior of the muscles were introduced on ABAQUS by using a user defined subroutine (UMAT) (Parente et al. 2009). In order to implement the 3 layer elastic parameters for the eardrum, a finite element mesh with 3 layers of elements with different properties was used, where the internal and external layers were considered as isotropic and the middle one, fibrous, was considered as orthotropic. For the boundary conditions, one layer of nodes around the pars tensa was fixed, and the free extremities of ligaments and muscles were also fixed.

Boundaries of the finite element model include the pars tensa of the eardrum periphery to simulate the tympanic annulus; the connection between the stapes footplate and the cochlea, in the oval window, to simulate the stapes annular ligament, where the free extremities of these elements are fixed, while the others are connected to the stapes nodes; the connection of suspensory ligaments and muscles to the temporal bone (superior of the malleus and superior of the incus simulate the tegmen, posterior of the incus simulates the fossa incudis and anterior of the malleus simulate the anterior wall of the tympanic cavity). The TTM is fixed in the handle of the malleus with lateral direction and the SM in the posterior crus of the stapes (Figure 5). The cochlear fluid is modelled with fluid elements, of type F3D3, assuming an incompressibility condition. The connection between the malleus and the incus, simulating the incudomallear joint, is done using contact formulation. In this sense, the basic Coulomb friction model available in the ABAQUS software is used, being the friction rate equal to 0.7 (Gentil et al. 2007).

Sound pressure is the pressure deviation from the local ambient pressure caused by a sound wave. Sound pressure level $(S P L)$ is a logarithmic measure of the sound pressure $(p)$ for a sound relative to a reference value $\left(p_{0}\right)$. It is measured in decibels (dB SPL) (Zemlin 1988) and can be defined by:

$$
S P L=20 \times \log _{10}\left(\frac{p}{p_{0}}\right),
$$

where the reference sound pressure is equal to $20 \mu \mathrm{Pa}$, corresponding to the audibility threshold.

Figure 5

\subsection{Material Properties and Constitutive models}

In the present work, the ossicles are assumed to have isotropic behavior, with elastic properties summarized in Table 1. The eardrum was divided into pars flaccida (with only one layer) and pars tensa (with three layers). The pars flaccida was considered as isotropic with Young's modulus equal to $1.00 \times 10^{7} \mathrm{~N} / \mathrm{m}^{2}$, like the internal and external layers of the pars tensa. The middle layer of the pars tensa is modeled as orthotropic material with tangential Young's modulus $\left(\mathrm{E}_{\theta}\right)$ of $2.00 \times$ $10^{7} \mathrm{~N} / \mathrm{m}^{2}$ and radial Young's modulus $\left(\mathrm{E}_{\mathrm{r}}\right)$ of $3.20 \times 10^{7} \mathrm{~N} / \mathrm{m}^{2}$ (Table 1 ). The Poisson's ratio is assumed equal to 0.3 for all materials with $\gamma=0 \mathrm{~s}^{-1}$ and $\beta=0.0001 \mathrm{~s}$, as the damping coefficients (Prendergast et al. 1999; Sun et al. 2002). The malleus and the incus were divided in different areas and the values for the density are shown in Table 1 . The stapes takes the same value throughout. The value of Young's modulus, for ossicles, was assumed equal to $1.41 \times 10^{10} \mathrm{~N} / \mathrm{m}^{2}$.

Table 1

Table 2 
The strain-energy function $\Psi$, for the Yeoh model (Yeoh 1990) can be written as (Holzapfel 2000):

$$
\Psi=c_{1}\left(I_{1}-3\right)+c_{2}\left(I_{1}-3\right)^{2}+c_{3}\left(I_{1}-3\right)^{3},
$$

where $c_{1}, c_{2}$ and $c_{3}$ are the material constants (Table 2). These constants were based in the work of Wang (Wang et al 2007). The deformation gradient tensor, $\mathbf{F}$, is defined as:

$$
F=\left(\begin{array}{lll}
\frac{\partial x_{1}}{\partial X_{1}} & \frac{\partial x_{1}}{\partial X_{2}} & \frac{\partial x_{1}}{\partial X_{3}} \\
\frac{\partial x_{2}}{\partial X_{1}} & \frac{\partial x_{2}}{\partial X_{2}} & \frac{\partial x_{2}}{\partial X_{3}} \\
\frac{\partial x_{3}}{\partial X_{1}} & \frac{\partial x_{3}}{\partial X_{2}} & \frac{\partial x_{3}}{\partial X_{3}}
\end{array}\right)
$$

where $\left(X_{1}, X_{2}, X_{3}\right)$ represents the position of the particle in the reference configuration and $\left(\mathrm{x}_{1}, \mathrm{x}_{2}\right.$, $\mathrm{X}_{3}$ ) its position in the current configuration. Assuming an uniaxial tension state for the ligaments, the particular form of $\mathbf{F}$ is

$$
\mathbf{F}=\left(\begin{array}{ccc}
\lambda & 0 & 0 \\
0 & \frac{1}{\sqrt{\lambda}} & 0 \\
0 & 0 & \frac{1}{\sqrt{\lambda}}
\end{array}\right)
$$

For a tension applied along the direction $\mathrm{x}_{1}$, taking $\lambda_{1}=\lambda$ and the incompressibility condition

$$
J=\prod_{i=1}^{3} \lambda_{i}=\operatorname{det}(\mathbf{F})=1
$$

one can obtain $\lambda_{2}=\lambda_{3}=\frac{1}{\sqrt{\lambda}}$.

The right Cauchy-Green tensor can then be established from equation (4):

$$
[\mathbf{C}]=[\mathbf{F}]^{T}[\mathbf{F}]=\left[\begin{array}{ccc}
\lambda^{2} & 0 & 0 \\
0 & \lambda^{-1} & 0 \\
0 & 0 & \lambda^{-1}
\end{array}\right]
$$

The Cauchy stress, as a function of the strain invariants can then be established:

$$
T=2\left(\lambda^{2}-\frac{1}{\lambda}\right)\left(\frac{\partial \Psi}{\partial I_{1}}\right)
$$

Using this invariant form and the strain-energy function $\Psi$ defined in equation (2), the uniaxial Cauchy stress for the Yeoh model is obtained:

$$
T_{Y e o h}=2\left(\lambda^{2}-\frac{1}{\lambda}\right)\left(c_{1}+2 c_{2}\left(I_{1}-3\right)+3 c_{3}\left(I_{1}-3\right)^{2}\right)
$$


Here, $I_{1}$ the first right Cauchy-Green strain tensor invariant $I_{1}=\operatorname{tr}(\mathbf{C})$, which can be expressed as:

$$
I_{1}=\lambda^{2}+\frac{2}{\lambda}
$$

\subsection{The constitutive model for muscles}

The constitutive model adopted in this work, for the middle ear muscles, is a modified form of the incompressible transversely isotropic hyperelastic model proposed by Martins et al. (1998), based on the work of Humphrey and Yin (1987). The resulting model is consistent with the 1-D models proposed by Hill (1938) and Zajac (1989). The strain energy function, per unit volume, can be written in the following form on the reference configuration:

$$
U=U_{I}+U_{f}
$$

This strain energy density function is the sum of a term related to the embedding matrix $\left(U_{I}\right)$ assumed isotropic and a fiber term $\left(U_{f}\right)$, where $U_{I}$ is defined as:

$$
U_{I}=c\left\{\exp \left[b\left(I_{1}-3\right)\right]-1\right\}
$$

where "c" and "b" are constants with values $8.21 \times 10^{2} \mathrm{~Pa}$ and 1.79 , respectively.

In equation (10), $U_{f}$ can be divided into a passive elastic part $U_{P E}\left(\lambda_{f}\right)$ and an active part $U_{S E}\left(\lambda_{f}, \alpha\right)$, due to the contraction. For the passive strain energy, the following expression was used:

$$
U_{P E}\left(\lambda_{f}\right)=A\left\{\exp \left[a\left(\lambda_{f}-1\right)^{2}\right]-1\right\}
$$

where "A" is a constant equal to $584 \mathrm{~Pa}$ and "a" equal to 12.43.

$\lambda_{f}$ is the fiber stretch ratio in the direction $\mathbf{N}$ of the undeformed fiber:

$$
\lambda_{f}=\sqrt{\mathbf{N}^{T} \mathbf{C N}}=\sqrt{\mathbf{C}:(\mathbf{N} \otimes \mathbf{N})}
$$

where $\otimes$ represents the tensor product and : represents a double contraction.

The isometric tension produced by the muscle, for a given $\lambda_{\mathrm{f}}$, is defined by the activation parameter $\alpha$ and by $\mathbf{T}_{0}^{M}$, the maximum tension produced by the muscle at resting length. The activation parameter can vary between $0 \%$ (passive state) and 100\% (complete activation). The maximum isometric tension that a muscle can generate depends strongly on $\lambda_{\mathrm{f}}$. If $\lambda_{\mathrm{f}}$ is too small or too large, the tension drops to zero. The maximum tension that is possible to obtain is equal to $\mathbf{T}_{0}^{M}$ and is obtained when $\lambda_{\mathrm{f}}=\mathrm{l}$ and $\alpha=1$.

For the strain energy due to the contraction, the following expression was used:

$$
U_{S E}\left(\lambda_{f}, \alpha\right)=T_{0}^{M} \int_{1}^{\lambda_{f}} f_{S E}\left(\lambda^{M}, \alpha\right) d \lambda^{M}
$$

where $\alpha$ is the activation level, varying between 0 and 1 .

For the function $f_{S E}\left(\lambda^{M}, \alpha\right)$ the following expression was used: 


$$
f_{S E}\left(\lambda^{M}, \alpha\right)=\alpha\left\{\begin{aligned}
1-4\left(\lambda^{M}-1\right)^{2}, & \text { for } 0.5<\lambda^{M}<1.5 \\
0, & \text { otherwise }
\end{aligned}\right.
$$

which means that for values of $0.5 \geq \lambda^{M} \geq 1.5$ the muscle produces no energy (D'Aulignac et al. 2005).

The maximum tension produced by the muscle at resting length, $\mathbf{T}_{0}^{M}$, equal to $66.82 \times 10^{3} \mathrm{~Pa}$, can also be defined by:

$$
\mathbf{T}_{0}^{M}=\frac{\mathbf{F}_{0}^{M}}{A_{0}}
$$

where, $\mathbf{F}_{0}^{M}$ is the peak isometric muscle force and $A_{0}$ is the muscle physiological cross section area.

\section{RESULTS AND DISCUSSIONS OF THE EFFECTS OF MUSCLES’ ACTIVATION}

The main purpose of this study is to determine realistic muscle configurations. In this sense, we consider equal activation for both muscles, the tensor tympani muscle (TTM) and the stapedius muscle (SM), for a sound pressure level, applied in the eardrum of $130 \mathrm{~dB}$ SPL (63.246 Pa).

Figure 6

Figure 6 shows, for different frequencies $(100,800,2 k$, 3k and $4 \mathrm{k} \mathrm{Hz})$ the decrease of stapes footplate pressure, when varying the activation level on the two muscles.

When compared to higher frequencies, differences in the footplate pressure are more noticeable for lower frequencies. After $3 \mathrm{kHz}$, the pressure obtained in the stapes footplate is almost the same with and without activation. To have the muscle contraction effect, only a short activation level is needed. If an activation level of $10 \%$ is used, two muscles contract and, for bigger values of activation, the same behaviour is obtained.

In Figure 7 it is possible to verify the pressure obtained at the central part of the stapes footplate, for frequencies ranging between $100 \mathrm{~Hz}$ and $10 \mathrm{kHz}$, with the two muscles in their passive state i.e. with activation equal to zero, and with two activation levels $(0.25$ and 0.5$)$ applied on them. The biggest differences occur for low and middle frequencies, being insignificant for frequencies exceeding $3 \mathrm{kHz}$.

Figure 7

When the muscles are passive, the pressure value obtained in the stapes footplate ranges from $1.4 \times$ $10^{4} \mathrm{~Pa}$, for lower frequencies, down to about $0 \mathrm{~Pa}$, for higher frequencies.

Figure 8

Subsequently, the activation of the TTM was fixed as passive and the SM was considered as passive, and with $25 \%$ and $50 \%$ of activation (Figure 8 ).

If the inverse simulating procedure is performed, i.e. the SM activation was passive, by varying the TTM activation level, one obtain the results shown in Figure 9.

Figure 9 
Compared with the inverse procedure, only for the middle frequencies a slight decrease of the pressure on the stapes footplate is observed (Figure 9). The results obtained indicate that if only one of the two muscles is activated, the obtained pressures are similar to the ones obtained when the two muscles are active.

Figure 10 shows the displacement of the central part of the stapes footplate when both muscles are passive and with activation level of $50 \%$ and $100 \%$.

It can be seen that with the increase of activation, the displacement decreases for frequencies lower than $3 \mathrm{kHz}$.

\section{Figure 10}

In Figure 11, the displacements of the stapes footplate are observed when the TTM is considered passive and the SM with 50\% and 100\% of activation. In Figure 12, the simulation procedure was the inverse i.e. the SM is considered passive and the TTM with $50 \%$ and $100 \%$ of activation. Comparing Figures 11 and 12, one can verify that there are no significant differences in the findings obtained.

\section{Figure 11}

\section{Figure 12}

Figure 13 shows the displacements obtained in the central part of the stapes footplate considering different pressures applied in the eardrum. It can be seen that for frequencies above $3 \mathrm{kHz}$ the displacements obtained for $120 \mathrm{~dB}$ SPL are near to the results obtained when applying a sound pressure level corresponding to $130 \mathrm{~dB}$ SPL but with maximal activation of the muscles.

The same occurs with the displacements obtained for $110 \mathrm{~dB}$ SPL and the ones obtained when applying a sound pressure level corresponding to $120 \mathrm{~dB}$ SPL but with maximal activation of the muscles.

\section{Figure 13}

\section{CONCLUSIONS}

The muscles of the middle ear (TTM and SM) can influence the transmission of sound along the ossicular chain. These muscles react in response to loud sounds, reducing the sound transmission to the inner ear (the acoustic reflex). When applying a sound pressure equivalent to $130 \mathrm{~dB}$ SPL in the eardrum, the activation of muscles causes a decrease in pressure obtained at the stapes footplate, especially in the low and middle frequencies, with no significant influence on frequencies above 3 $\mathrm{kHz}$, which is consistent with the clinical practice data (Humes 1978).

The clinical practice shows that the auditory system still works well without one of the muscles. An example is the surgical procedure called Stapedectomy where the stapes is replaced by prosthesis and the stapedius muscle is usually removed.

When analyzing the displacements obtained in the stapes footplate and comparing different pressures applied in the eardrum, one can conclude that the muscle activation allows a reduction of about $10 \mathrm{~dB}$ to reach the inner ear, thereby protecting it from further damage, which also agrees with the clinical practice data (Humes 1978).

We can conclude that if only one of the two muscles is activated, it promotes similar behavior when two active muscles are compared. This may explain the fact that people subjected to surgery (Stapedotomy or Stapedectomy), where the stapedius muscle is cut, still present a good tolerance to loud sounds. 
Despite the function of muscle activation, there is no great loss when one of the two muscles is ineffective. If two muscles are injured, it can be expected that people may feel uncomfortable with strong intensity sounds and in low frequencies.

\section{ACKNOWLEDGMENTS}

The authors would like to thank the Ministério da Ciência, Tecnologia e Ensino Superior Fundação para a Ciência e a Tecnologia in Portugal and by FEDER for the funding provide under the research projects with the references PTDC/SAU-BEB/104992/2008, PTDC/EEACRO/103320/2008, UTAustin/CA/0047/2008 and UTAustin/MAT/0009/2008.

The authors also would like to thank to Belinha for collaboration provided in the figures drawn.

\section{REFERENCES}

ABAQUS Analyses User's Manual. Version 6.5, 2007.

D'Aulignac, Martins JAC, Pires EB, Mascarenhas T, Natal RM. 2005. A Shell Finite Element Model of the Pelvic Floor Muscles, Computer Methods in Biomechanics and Biomedical Engineering, 8:339-347.

Fung YC. 1981. Biomechanics: Mechanical Properties of living tissues. Springer-Verlag, New York.

Gan RZ, Feng B, Sun Q. 2004. Three-Dimensional Finite Element Modeling of Human Ear for Sound Transmission, Annals of Biomedical Engineering. Vol. 32, No 6:847-859.

Garbe C, Gentil F, Parente M, Martins P, Natal Jorge R. 2009. Aplicação do método dos elementos finitos no estudo da membrana timpânica. Audiologia em Revista. Volume II, No 3: 99-106.

Gentil F, Jorge RMN, Ferreira AJM, Parente MPL, Martins PALS, Almeida E. 2006. Biomechanical simulation of middle ear using hyperelastic models, Journal of Biomechanics. 39, Supplement 1:388-389.

Gentil F, Jorge RM N, Ferreira AJM, Parente MPL, Moreira M, Almeida E. 2007. Estudo do efeito do atrito no contacto entre os ossículos do ouvido médio, Revista Internacional de Métodos Numéricos para Cálculo y Diseño en Ingeniería. Vol. 23, 2:177-187.

Gentil F. 2008. Estudo Biomecânico do Ouvido Médio. PhD Thesis. Porto, Portugal: Universidade do Porto.

Gentil F, Natal R, Parente M, Martins P, Ferreira A. 2009. Estudo Biomecânico do Ouvido Médio. Clínica e Investigação em Otorrinolaringologia, 3:24-30.

Gray H. 1918. Anatomy of the Human Body Philadelphia, Lea \& Febiger.

Herman IP. 2007. Physics of the human body. Springer.

Hill AV. 1938. The heart of shortening and the dynamic constants of muscle, Proc. R. Soc. Biol., 126:136-195.

Holzapfel GA. 2000. Nonlinear solid mechanics. John Wiley \& sons, Ltd., New York.

Humes LE. 1978. The Effects of Middle Ear Muscle Contraction on Auditory and Overload Thresholds, Audiology, 17:360-367.

Humphrey JD, Yin FCP. 1987. On constitutive relations and finite deformations of passive cardic tissue: I. A 
pseudostrain-energy function, ASME J. Biomech. Engrg. 109:298-304.

Isaacson JE and Vora NM. 2003. Differential Diagnosis and Treatment of Hearing Loss, American Academy of Family Physicians. 68:1125-32.

Katz J, Gabbay WL, Gold S, Medwetsky L, Ruth RA. 1991. Handbook of clinical audiology, University at Buffalo, New York.

Koike T, Wada H, Kobayashi T. 2002. Modeling of the human middle ear using the finite-element method. J. Acoust. Soc. Am. 111:1306-1317.

Martins JAC, Pires EB, Salvado R, Dinis PB. 1998. A Numerical model of passive and active behavior of skeletal muscles. Computer methods in applied mechanics and engineering. Vol. 151:419-433.

Martins PALS, Jorge RMN, Ferreira AJM. 2006. A Comparative Study of Several Material Models for Prediction of Hyperelastic Properties: Application to Silicone-Rubber and Soft Tissues. Strain. 42:135-147.

Paço J. 2003. Doenças do tímpano. Lidel, Lisboa.

Paço J, Branco C, Estibeiro H, Carmo DO. 2009. The posterosuperior quadrant of the tympanic membrane. Otolaryngology - Head and Neck Surgery. 140:884-888.

Parente M, Jorge RMN, Mascarenhas T, Fernandes AA, Martins JAC. 2009. The influence of the material properties on the biomechanical behavior of the pelvic floor during a vaginal delivery. Journal of Biomechanics. 42:1301-1306.

Prendergast PJ, Ferris P, Rice HJ, Blayney AW. 1999. Vibro-Acoustic Modelling of the Outer and Middle Ear using the Finite-Element Method. Audiol Neurootol. 4:185-191.

Putz, R, Pabst, R. 2001. Sobotta_v1.5 - Atlas of Human Anatomy, 13th Edition.

Stach BA. 1987. The Acoustic Reflex in Diagnostic Audiology: From Metz to Present. Ear and Hearing, The Williams \& Wilkins Co. 8,36S-42S.

Sun Q, Gan RZ, Chang KH, Dormer KJ. 2002. Computer-integrated finite element modeling of human middle ear. Biomechanics and Modeling in Mechanobiology. 1:109-122.

Testut L. 1920. Traité d’Anatomie humaine - organes des sens, tome septieme.

Tilman CS. 2005. International bureau for audiophonology (BIAP) recommendations, Belgium.

Yeoh OH. 1990. Characterization of elastic properties of car-bon-black-filled rubber vulcanizates, Rubber Chemistry and Technology, 63:792-805.

Wang X, Cheng T, Gan RZ. 2007. Finite-element analysis of middle ear pressure effects on static and dynamic behavior of human ear. J. Acoust. Soc. Am., 122(2):906-917.

Zajac FE. 1989. Muscle and tendon: Properties, models, scaling and application to biomechanics and motor control, CRC Critical Reviews in Biomedical Engineering, 17:359-411.

Zemlin WR. 1988. Speech and Hearing Science: Anatomy and Physiology. Englewood Cliffs, Ptentice-Hall. 


\section{TABLES}

Table 1. Material properties for the eardrum, ossicles and ligaments.

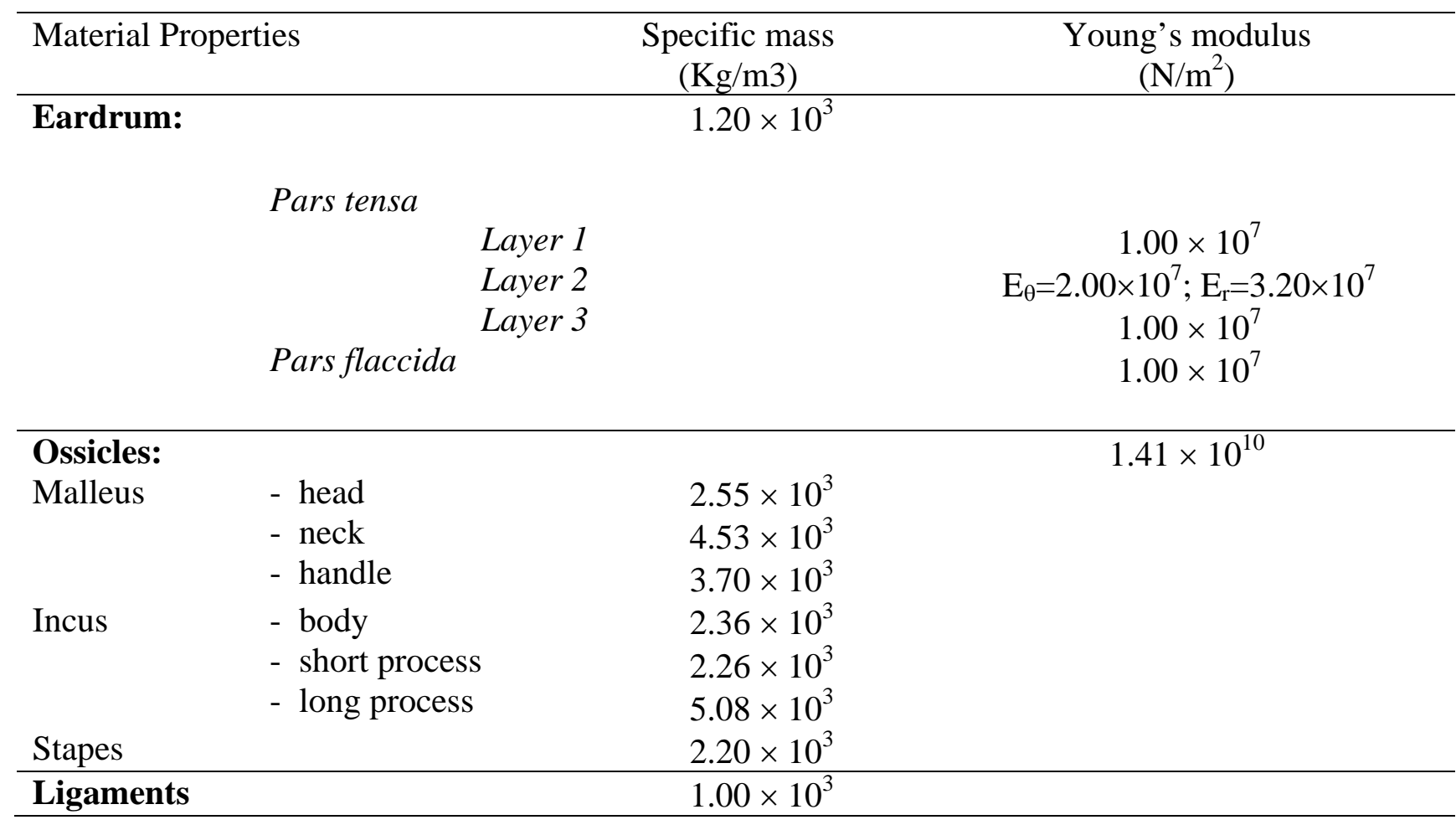

Table 2. Properties for ligaments (Martins et al. 2006).

\begin{tabular}{llccc}
\hline \multicolumn{2}{l}{ Ligaments constants } & $c_{1}$ & $c_{2}$ & $c_{3}$ \\
\hline Malleus & - superior & $6.3064 \times 10^{3}$ & $-9.9999 \times 10^{3}$ & $2.2045 \times 10^{6}$ \\
& - anterior & $7.3387 \times 10^{4}$ & $-3.7438 \times 10^{2}$ & $5.8557 \times 10^{5}$ \\
\multirow{2}{*}{ Incus } & - lateral & $6.3064 \times 10^{3}$ & $-9.9999 \times 10^{3}$ & $2.2045 \times 10^{6}$ \\
& - superior & $6.3064 \times 10^{3}$ & $-9.9999 \times 10^{3}$ & $2.2045 \times 10^{6}$ \\
Stapes & - posterior & $5.4589 \times 10^{4}$ & $-4.1699 \times 10^{4}$ & $1.2548 \times 10^{6}$ \\
\hline
\end{tabular}




\section{FIGURES}

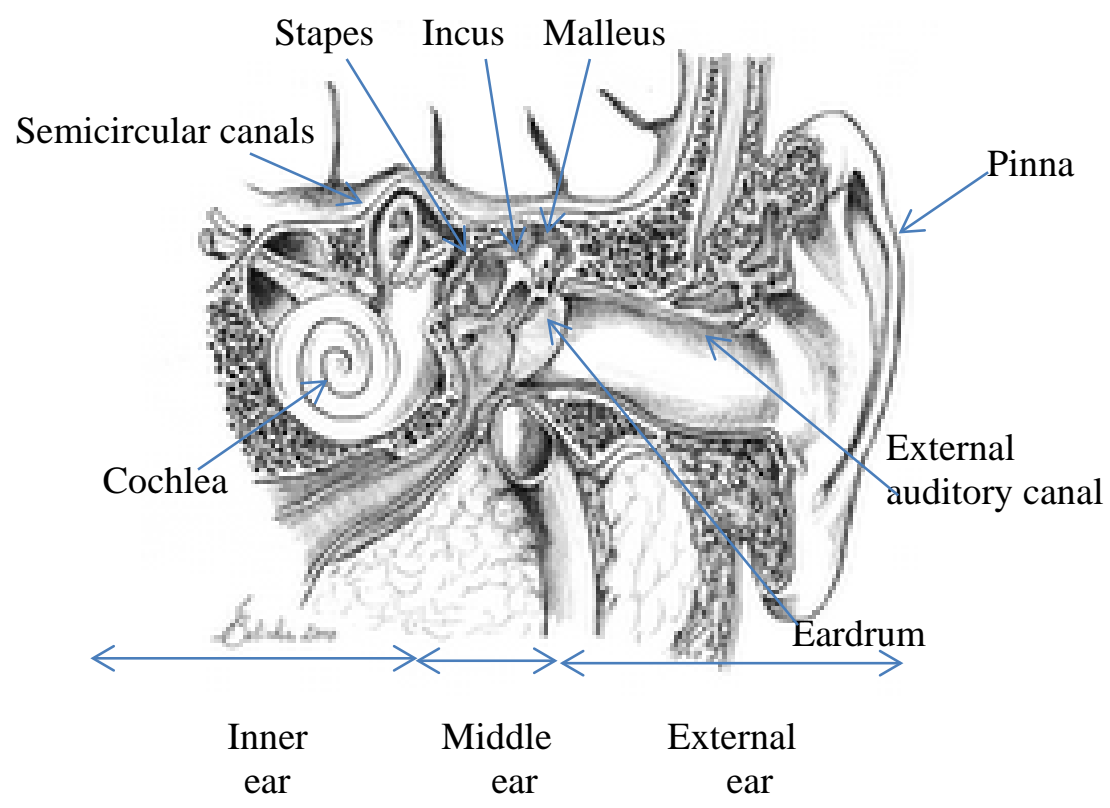

Figure 1. Depiction of the external, middle and inner ear.

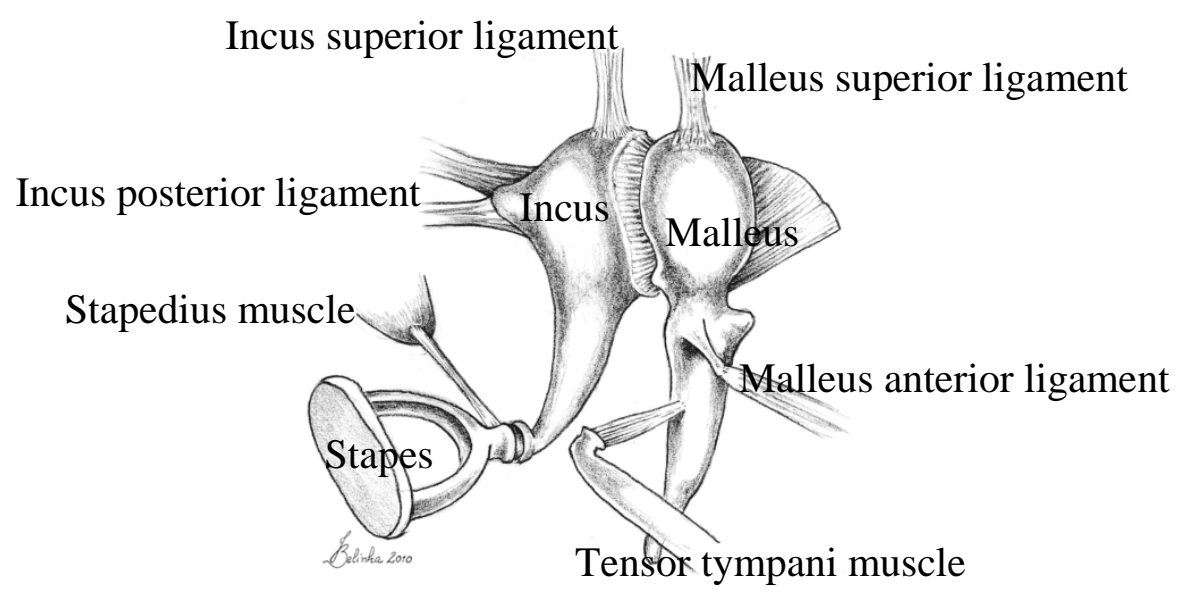

Figure 2. Depiction of the ossicular chain of the middle ear, including the ligaments and muscles (based on Sobotta). 


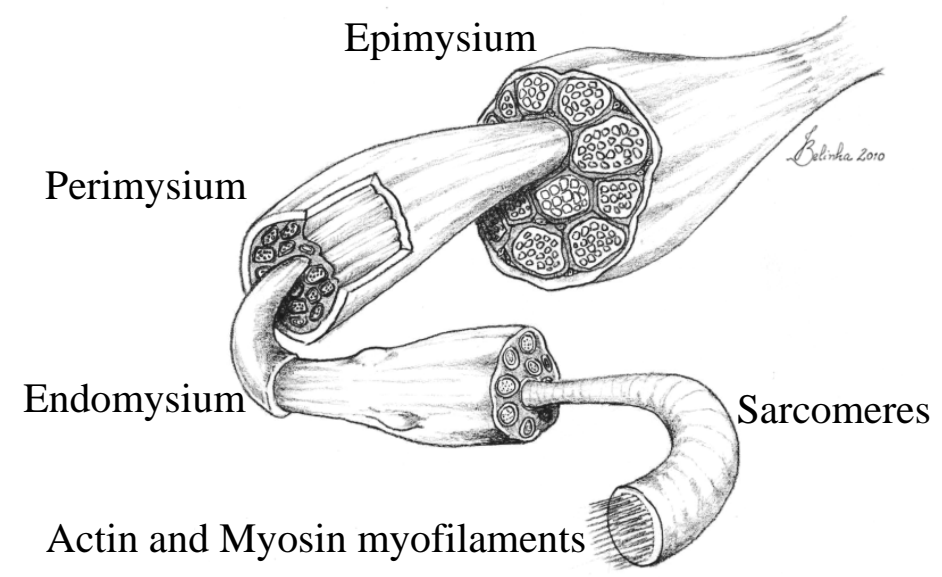

Figure 3. Structure of skeletal muscle, down to the myofibril level (based on Herman 2007).

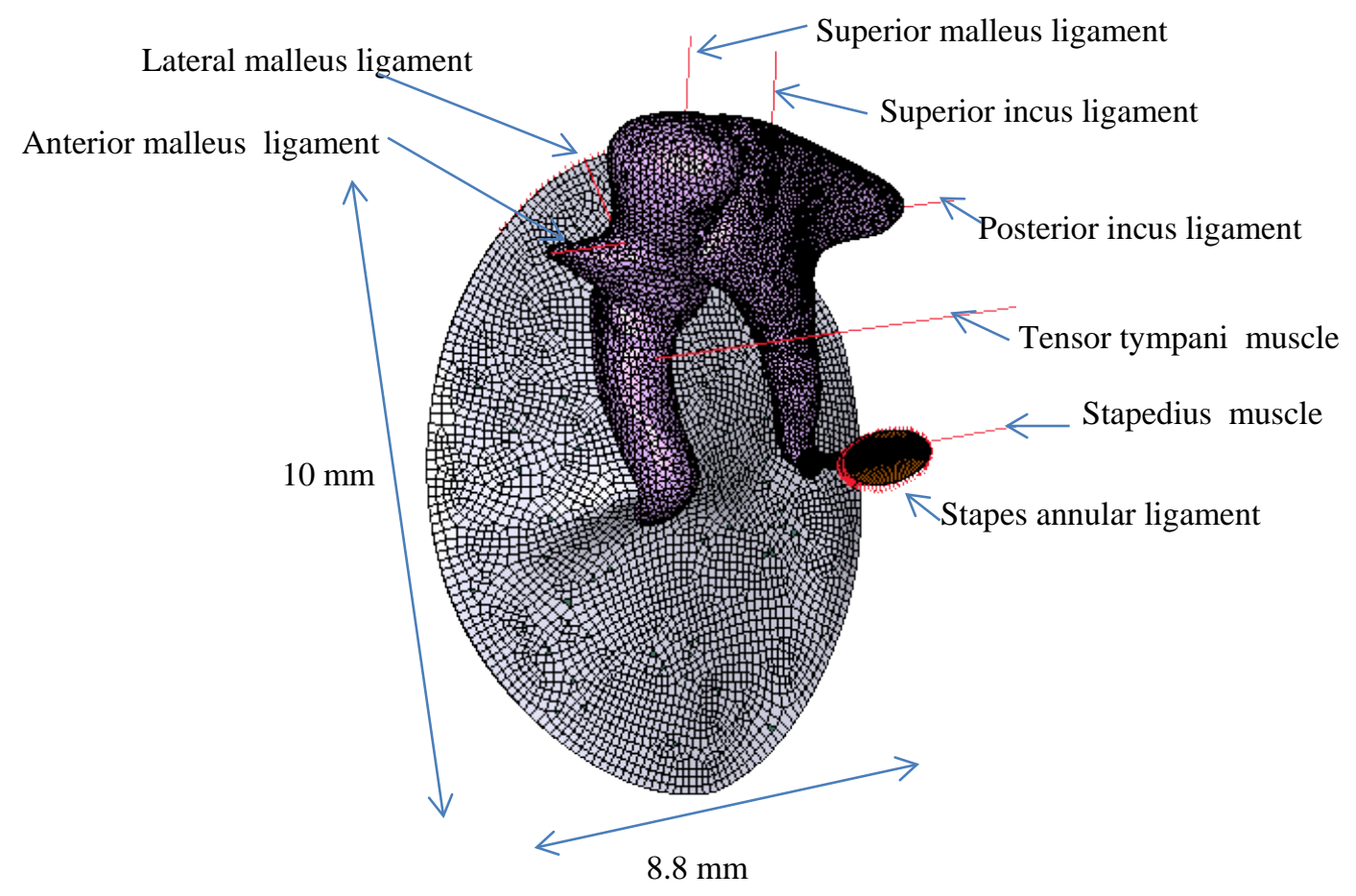

Figure 4. Finite element model built for the middle ear ossicles, eardrum, ligaments and muscles.

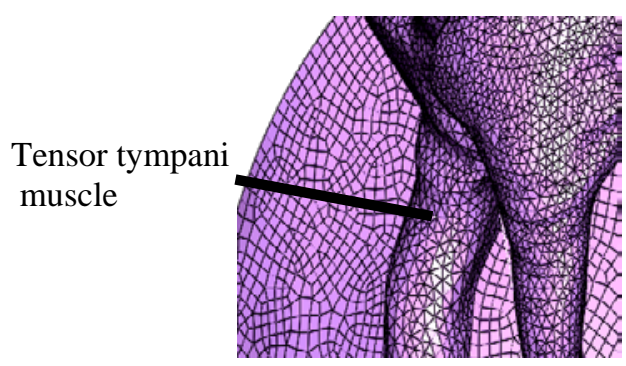

a)

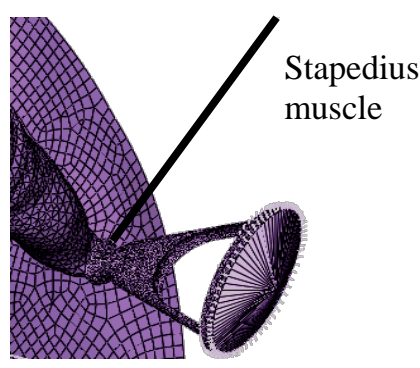

b)

Figure 5. Middle ear muscles: a) tensor tympanic muscle (TTM) and b) stapedius muscle (SM).

The load applied in the eardrum is simulated for uniform sound pressure levels of 110, 120 and 130 dB SPL. Thus, distributed normal loads of $6.325 \mathrm{~Pa}$ (for $110 \mathrm{~dB}$ SPL), $20 \mathrm{~Pa}$ (for $120 \mathrm{~dB}$ SPL) and 63.246 Pa (for $130 \mathrm{~dB}$ SPL) of sound pressure are applied in the eardrum. 


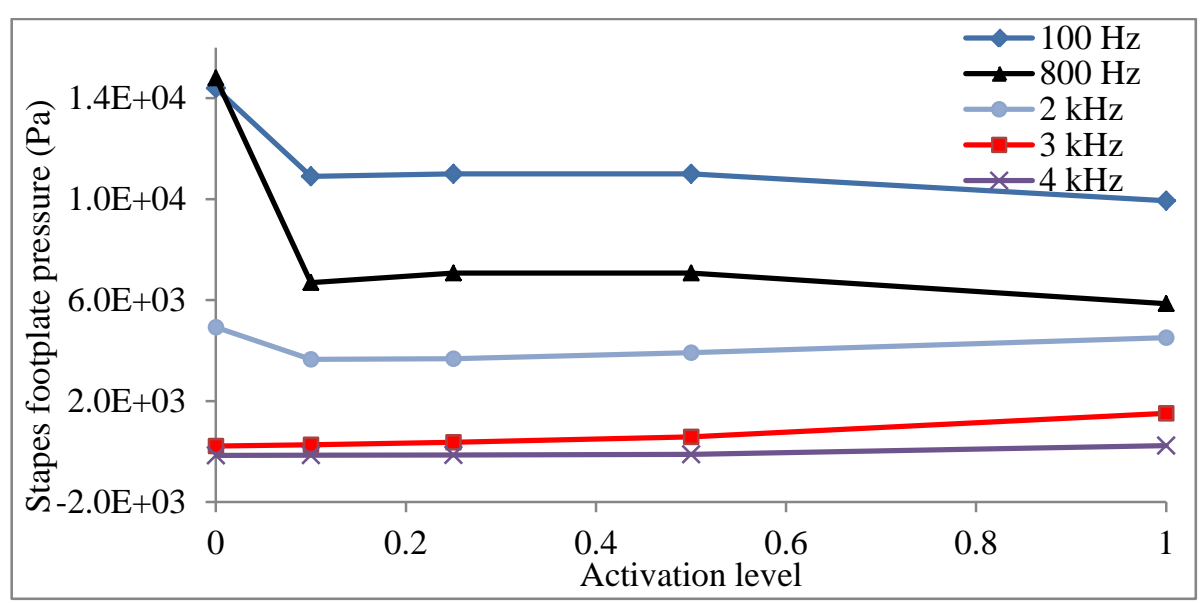

Figure 6: Stapes footplate pressure for different activation levels on the TTM and the $\mathrm{SM}$, for different frequencies.

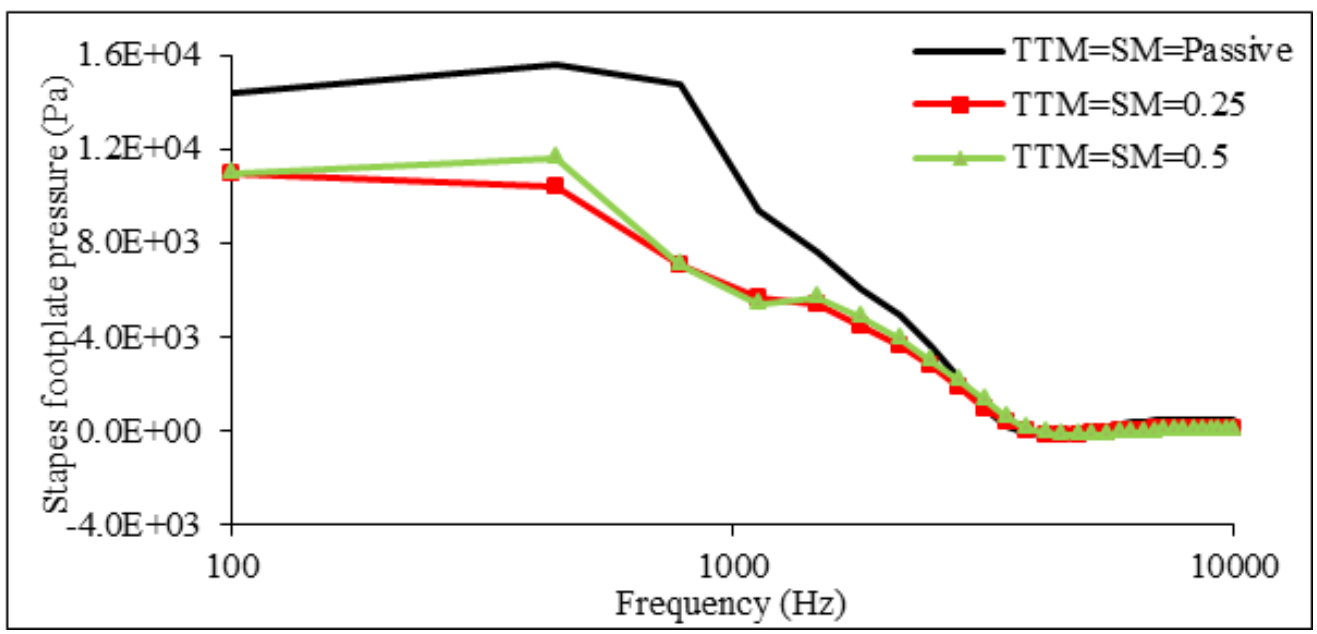

Figure 7: Pressure obtained in the stapes footplate with different values of muscles activation (two muscles without activation and with $25 \%$ and $50 \%$ of activation), for a sound pressure level of $130 \mathrm{~dB}$ SPL applied on the eardrum.

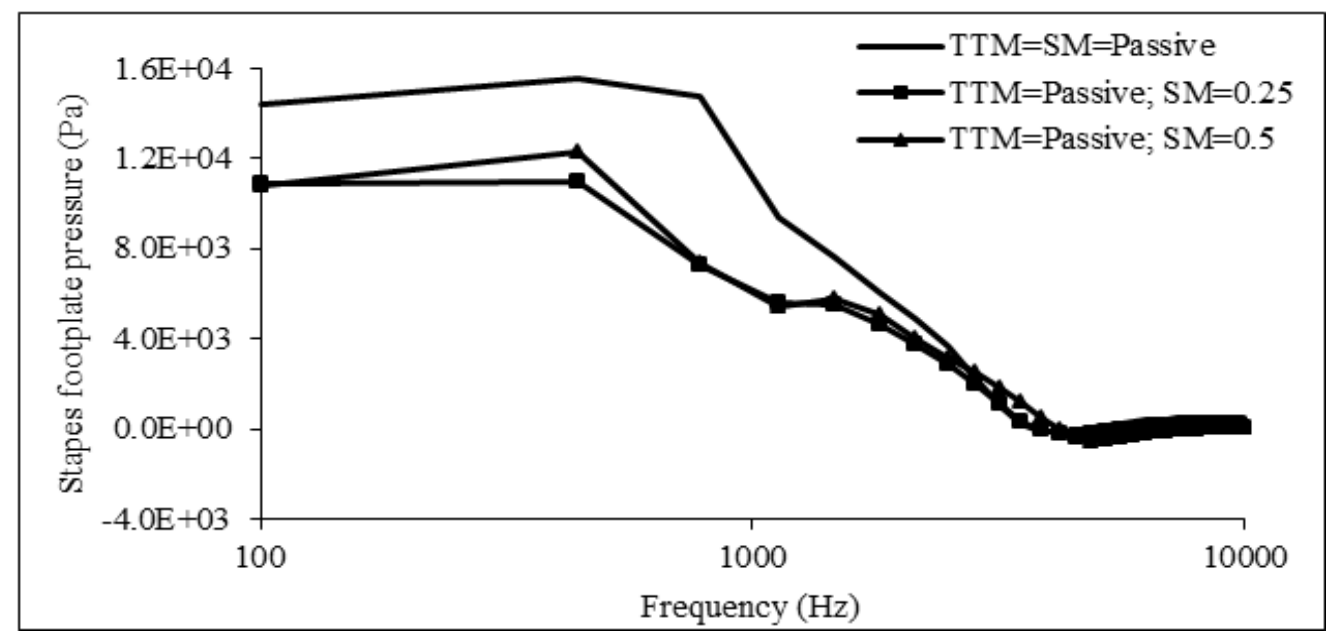

Figure 8: Pressure obtained in the stapes footplate with the TTM as passive, and the SM with three activation states (passive, $25 \%$ and $50 \%$ of activation). 


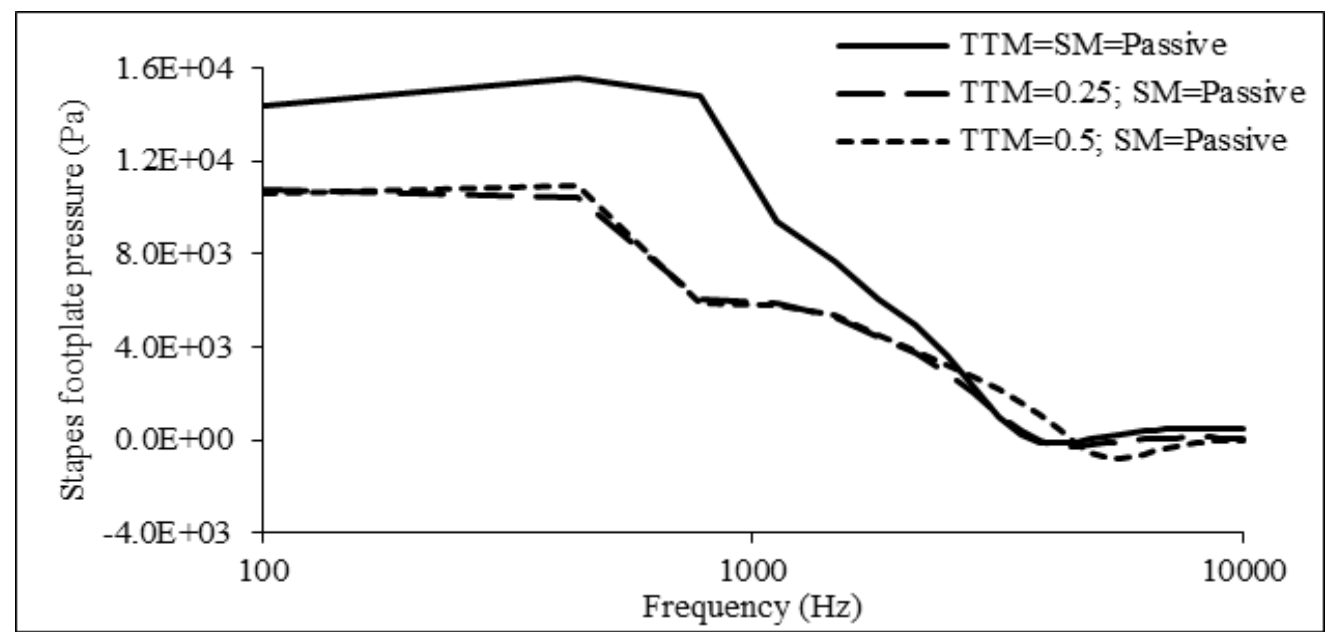

Figure 9: Pressure obtained in the stapes footplate with the SM as passive, and the TTM with three activation states (passive, $25 \%$ and $50 \%$ of activation).

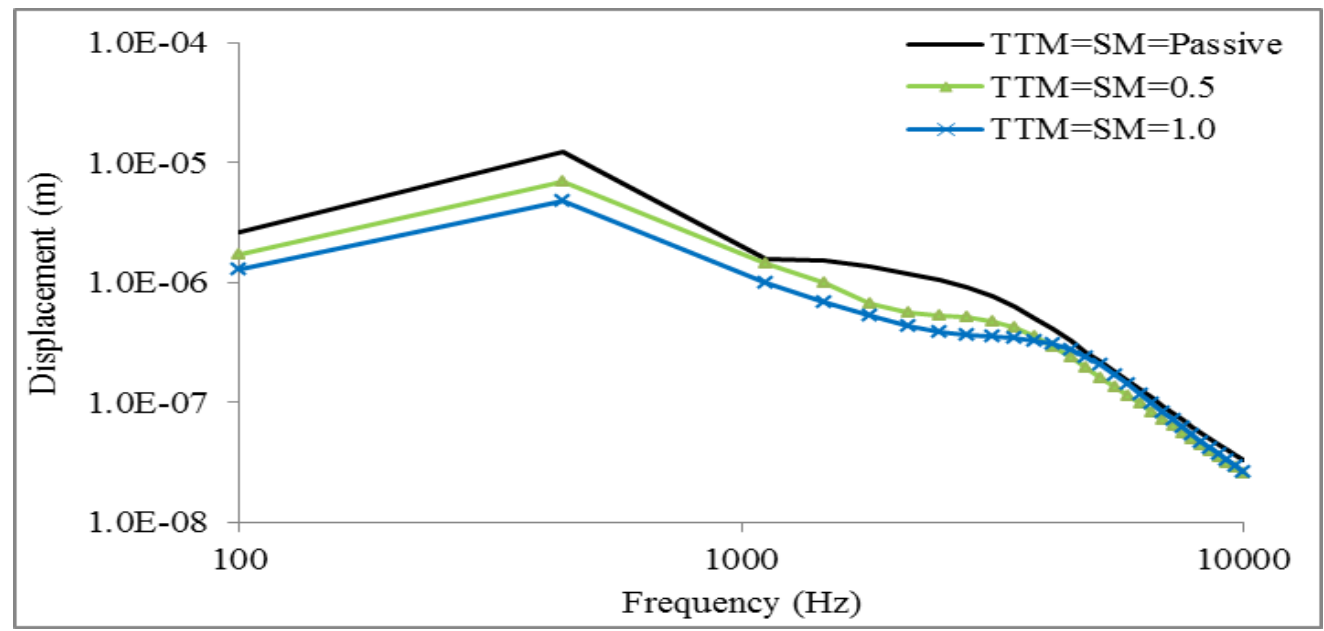

Figure 10: Stapes footplate displacement when considering the two muscles as passive and with $50 \%$ and $100 \%$ of activation.

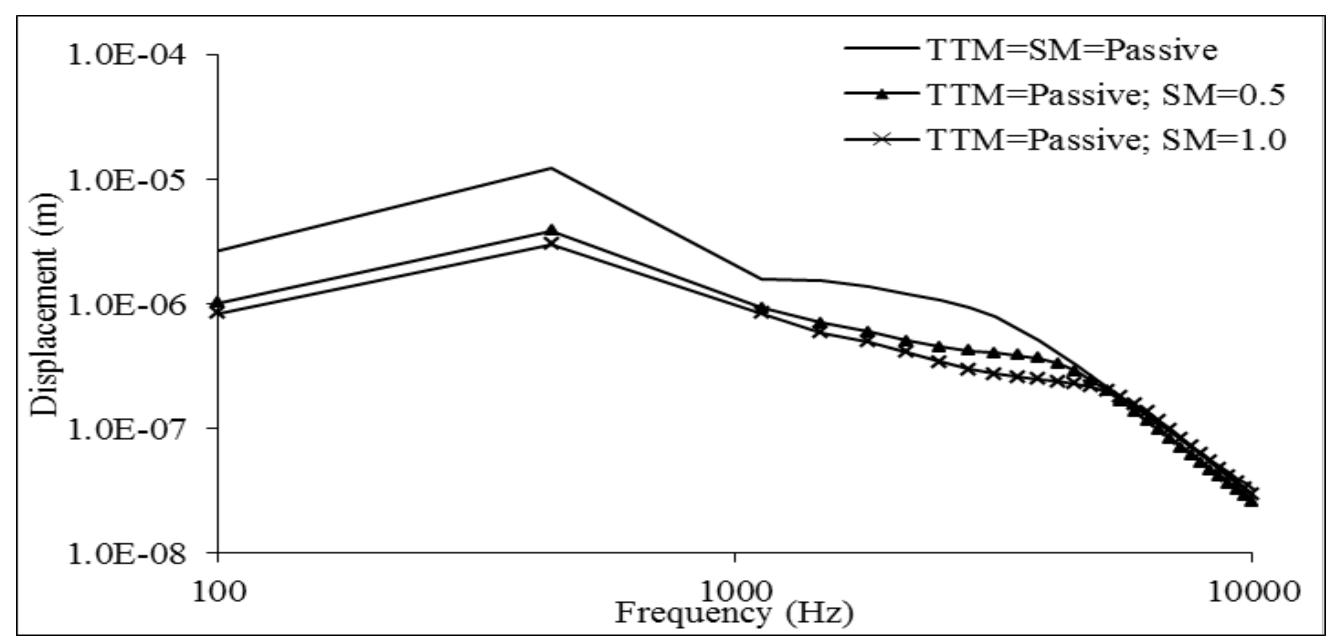

Figure 11: Stapes footplate displacement when considering the TTM as passive and the SM with three activation levels (passive, $50 \%$ and $100 \%$ of activation). 


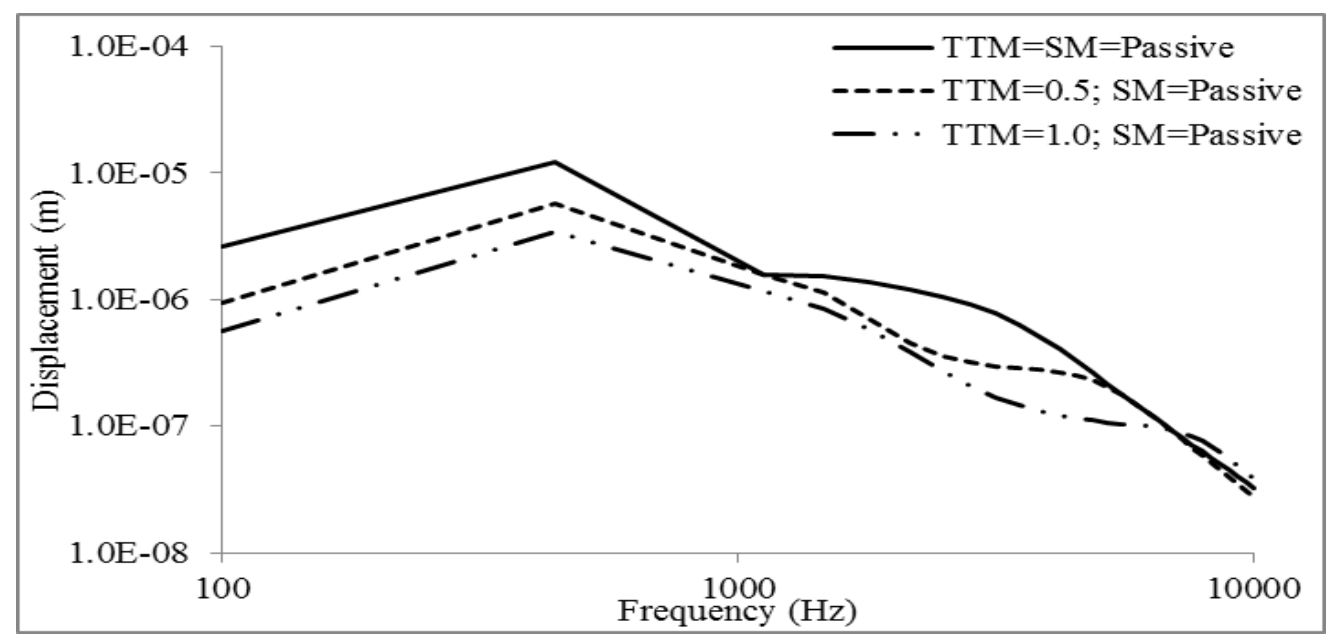

Figure 12: Stapes footplate displacement when considering the SM as passive and the TTM with three activation levels (passive, $50 \%$ and $100 \%$ of activation).

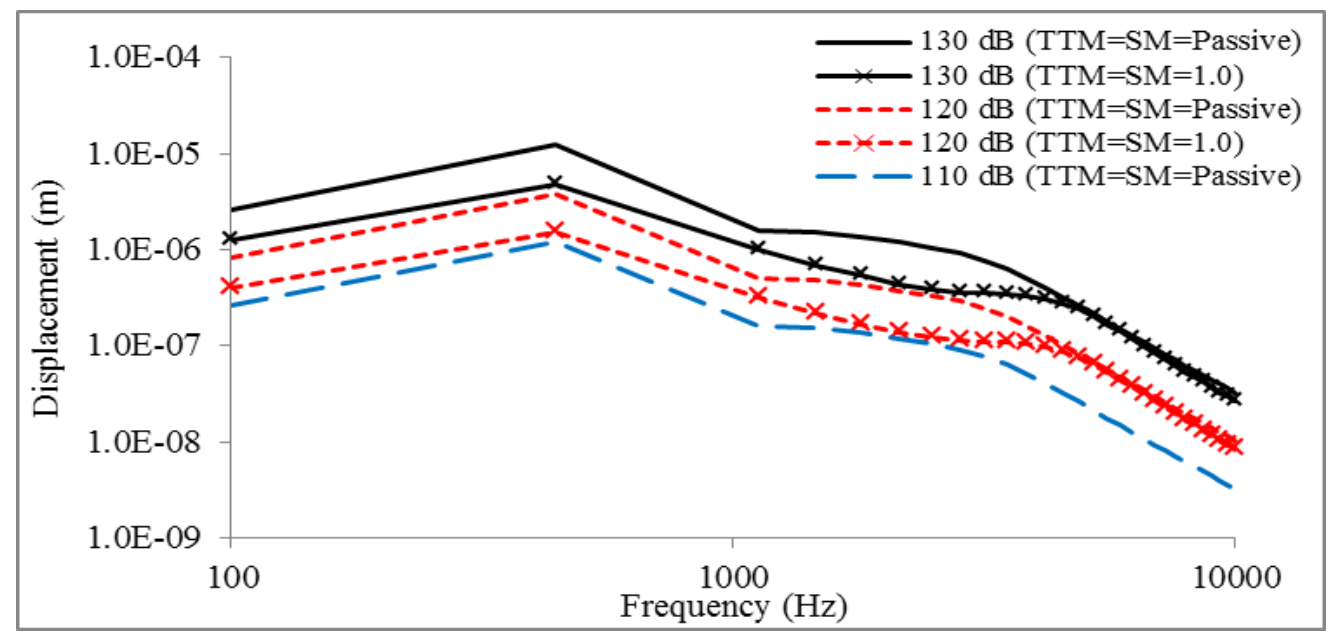

Figure 13: Stapes footplate displacement, for $130 \mathrm{~dB}$ SPL and $120 \mathrm{~dB}$ SPL (with the two muscles passive and with $100 \%$ of activation) and for $110 \mathrm{~dB}$ SPL (two muscles passive). 